\title{
Mathematics Awareness through Technology, Teamwork, Engagement, and Rigor
}

\author{
Laurie James ${ }^{1, *}$ \\ ${ }^{1}$ Education Division, University of Hawai'i - West O'ahu, Kapolei, HI 96707, USA \\ *Correspondence: Education Division, University of Hawai'i - West O’ahu, Kapolei, HI 96707, USA. E-mail: \\ ljames7@hawaii.edu
}

Received: July 30, 2016

Accepted: September 12, 2016 Online Published: October 10, 2016

doi:10.5430/jct.v5n2p55

URL: http://dx.doi.org/10.5430/jct.v5n2p55

\begin{abstract}
The purpose of this two-year observational study was to determine if the use of technology and intervention groups affected fourth-grade math scores. Specifically, the desire was to identify the percentage of students who met or exceeded grade-level standards on the state standardized test. This study indicated possible reasons that enhanced conceptual understanding within the study group at a Title I elementary school. Throughout the two-year time period, the classroom teachers created mathematics awareness through technology, teamwork, engagement and rigor. The findings revealed a significant percent of fourth-grade students who used technology and participated in specific learning activities met or exceeded grade-level standards in math as measured by the Washington State standardized test.
\end{abstract}

Keywords: conceptual understanding; discourse; engage; interactive whiteboard; intervention; rigor; Common Core State Standards for Mathematics

\section{Introduction}

Mathematics concepts can be difficult for elementary students to grasp. That is why it is important to create a classroom climate allowing students to feel comfortable to take risks, ask questions, and learn through inquiry. When having a deeper level of discussion, students can make their discoveries while talking about their thought process when solving problems (Zwiers \& Crawford, 2011). Through this process, students increase their need to know why something works in math, not just how it works. Understanding why and how to solve problems requires students to acquire the proper language and terminology (Zwiers, 2014). Therefore, providing students with a supportive infrastructure in math is vital to their success.

What steps help students deepen their understanding of new knowledge in the math classroom? First, daily instruction must build from prior lessons to engage students in thinking and learning about mathematics. Next, teachers need to be creative through a combination of integrated technology and intervention groups while providing a positive classroom atmosphere where students learn from each other. Teachers must help students acquire mathematical language (NCTM, 2000). Finally, students can expand their understanding through productive struggle. When students make mistakes experiencing productive struggle, their brain activity grows because synapse fires making new connections (Boaler, 2013).

This study illustrates how fourth-grade students enhanced their math skills on their way to becoming more mathematically literate. Math is more than just remembering facts and using formulas; it is about being able to explain your thinking, solve problems, and learn through productive struggle. This progression leads students to change their approach to mathematics and increase their academic drive creating a growth mindset. Students are creating a growth mindset when believing they can develop their mathematical ability reinforcing the idea that math is the process of learning not the product (Boaler, 2013). Mathematical concepts that students are in the process of constructing formulate over time (Van de Walle \& Lovin, 2006). In doing so, students acquire the ability to apply their knowledge in creating sophisticated products (Wiske, 2005).

One challenge in education is getting students at Title I schools to meet grade level standards on state academic assessments (Office of Superintendent of Public Instruction, 2016). Under current law, Title I provides financial 
assistance to local educational agencies and schools with high numbers or high percentages of children from low-income families to help these students meet state academic standards (U.S. Department of Education, 2010). To support the current needs of students who attend a Title I school the federal government provides additional funding to enhance instructional services and activities for the entire school. The intent is to support the academic achievement of students who are most at risk of failing (Office of Superintendent of Public Instruction, 2016). Therefore, the goal of a Title I school is to provide customized instruction to help students meet challenging academic standards and take an active role in the learning process.

\subsection{Background: Teaching Mathematics Effectively}

Before the start of the school year, it is necessary for teachers to collaborate to develop an instructional plan incorporating hands-on activities and technology to enrich student learning. There is an emphasis placed on how to teach the big ideas in math more effectively so students can make sense of mathematical problems and concepts (NCTM, 2000). Effective teachers ask students appropriate and timely questions that connect new ideas to big ideas. These big ideas in mathematics allow students to make connections by building background knowledge and enduring understanding.

To develop students' level of knowledge, teachers need to ask open-ended questions creating a more rigorous classroom setting. Rigor creates an environment in which students learn at high levels, articulate their thought process, and apply mathematical knowledge (Common Core State Standards Initiative, 2016). When mathematical rigor increases, the students develop cognitive skills through reflective thought and creativity.

The teachers must recognize the importance of immersing students with key mathematical vocabulary as well as provide opportunities to answer higher-level questions. It is necessary for students to comprehend complex ideas, so they solve problems and transfer their knowledge to new situations. Since all students have different experiences in math, students need to know the teacher's expectations for them as well as what they can expect from the teacher. When the teachers establish mathematical expectations, the students willingly interact among themselves (Marzano, 2007).

A math lesson design that uses interactive technology allows for higher levels of scaffolding (DeVita, Verschaffel, \& Elen, 2014). Instructional scaffolding helps to bridge learning gaps identifying what students learned and what they were expected to comprehend. For real learning to take place, there must be some challenge, some new ideas even if students merely saw an old idea in a new format (Van de Walle \& Lovin, 2006). The students' ideas should be valued and serve as a source of learning (NCTM, 2000).

Technology infused within the core curriculum requires a new way to teach and think about mathematical content. Understanding the role of technology in the classroom is an essential component in the students' learning development (Scoter \& Boss, 2004). A way to keep students on track would be to follow a pacing guide (Marzano, 2007). When teachers create a logical scope and sequence for their students, downtime decreases making it possible to expedite a pacing guide.

\subsection{Supporting Mathematics Instruction}

To support math instruction, the teachers must develop a well-rounded math program essential for student success. Students apply previously learned strategies to the problem, summarize main points, organize information in a logical way, and compare a problem to similar problems (Zwiers, 2014). Making math a priority, the students take a journey to become mathematicians. Becoming a mathematician does not just mean doing things a different way. Being a mathematician means taking action. These actions prepare the students for real-world mathematical problems as well as standardized tests.

The interactive whiteboard is a sensory, hands-on learning tool providing students with different learning styles to become more engaged in the lesson (DeVita, Verschaffel, \& Elen, 2014). Students who are tactile learners can touch and move things around on the interactive board while visual learners benefit from the information provided in a clear and organized fashion. The interactive whiteboard focuses instruction on the development of specific concepts and helps to improve students' mathematical knowledge. The students become skillful learners by adapting continuously.

The integration of the interactive whiteboard creates a collaborative classroom where students absorb information, talk about new knowledge, and reflect on how their understanding changes. Using an interactive whiteboard as an extension of the computer creates new opportunities for learning (Zevenbergen \& Lerman, 2008). The interactive whiteboard turns a traditional classroom whiteboard into a kinesthetic experience making it useful and engaging for 
students (Lever-Duffy \& McDonald, 2011). During the learning process, students can think and talk like mathematicians.

Teachers use flipcharts for each lesson as a way to share information through multiple electronic slides. Each flipchart is an electronic tool used to display mathematical concepts, save notes, and review previous content on a large, vertical display (Mercer, Hennessy, \& Warwick, 2010). The flipcharts make it simple for students to use the interactive technology while revising previous work (Scoter \& Boss, 2004). When students construct their understanding and test new ideas of mathematical concepts, how they are learning is as important as what they are learning (Van de Walle \& Lovin, 2006). As a result, this technology is an essential tool for both learning and teaching mathematics (Van de Walle, Karp \& Bay-Williams, 2016).

\subsection{Why having a Positive Classroom Atmosphere Matters}

At the beginning of the school year, it is important to create a positive classroom atmosphere allowing students to feel comfortable to take risks, ask questions, and learn from each other. When students think positively about themselves, they unlock their abilities and prevent stress from blocking their working memory (Boaler, 2013). The teacher models and guides students in ways to compliment and encourage each other. One way to ensure in-depth discourse is to provide sentence starters so students can articulate their thinking. Because of this form of dialogue, students gain confidence in their mathematical discourse and begin to share their thoughts openly. This rigorous, interactive environment empowers students to learn (Van de Walle, Karp \& Bay-Williams, 2016). Open communication allows the teachers to identify misconceptions students have regarding their learning. Also, the teacher needs to encourage students to ask questions when they do not understand (NCTM, 2000). Deep understanding develops over time (Hiebert \& Wearne, 2003). Reviewing mathematical content in groups helps gain a higher conceptual understanding of the material. Conceptual understanding is an important component of proficiency (NCTM, 2000).

Effective and accurate peer feedback is just as powerful as teacher feedback. When students provide each other with feedback, it shows they are listening and understanding what others are saying. Students check their thinking and look for ways to solve problems by using mathematical discourse. Students use the language of mathematics to express their thoughts building connections to formal mathematical terms (NCTM, 2000). The conversations help students develop vocabulary, syntax, background knowledge, and thinking skills (Zwiers \& Crawford, 2011).

Even though students may struggle, creating a risk-free setting where they can externalize their struggle creates opportunities for success (Hiebert \& Wearne, 2003). Conversations allow students to show what they know and what they can do (Zwiers \& Crawford, 2011). When having opportunities to discuss topics, students talk about their thought process making discoveries and expanding understanding of how the math works. This discovery helps students realize they are capable of doing well in mathematics (Boaler, 2013). When students share with each other, they expand on new mathematical concepts (Van de Walle, Karp \& Bay-Williams, 2016). Through the group discussions, students discover working together is fun.

Another notable technique used in the math classrooms is peer tutoring. During peer tutoring time, students work through problems and explain their mathematical reasoning to each other. While articulating their thoughts, students might think differently and struggle. This approach to learning provides opportunities to deepen their level of understanding they might have executed without thinking (Hiebert \& Wearne, 2003). Having in-depth conversations allows the students to process and clarify content (Zwiers \& Crawford, 2011). Because of this discourse, students use clear and precise language in their discussions with peers. Furthermore, the students develop a sense of pride and confidence to figure out and make sense of the mathematics (Van de Walle \& Lovin, 2006).

During a math work time, small groups of students relearn specific content with the assistance of the classroom teacher. The teacher bridges learning gaps by using a variety of instructional techniques to reinforce mathematics. Some students use the classroom computers to reinforce mathematical concepts which transfer their knowledge to other situations. Students might view computer activities as games, but instead the activities reinforce fundamental concepts including basic facts, geometry, measurement, fractions, and word problems.

\section{Methods}

The intent of this two-year study was to determine if students who used interactive technology and intervention groups in math would meet or exceed grade level standards. In the first year of this two-year study, there were 46 students in the fourth-grade study group. Participants selected for the study group consisted of all students enrolled in 
the two classrooms. This Title I elementary school had $74 \%$ of the students receiving free or reduced-priced meals and $34 \%$ of the students were transitional bilingual.

The second year of this study consisted of a different group of 50 fourth-grade students. Participants in the study group included all students enrolled in the two classrooms. The teachers used the same pacing guide, teaching techniques, and technology with this study group as they did the previous year. The same Title I elementary school had $77 \%$ of the students receiving free or reduced-priced meals and $36 \%$ of the students were transitional bilingual.

The common threads in the classrooms for all mathematic lessons were the interactive technology and intervention groups. The two teachers used the interactive whiteboard to review previous mathematical concepts and problems. The review would last approximately 20 minutes leaving 70 minutes to integrate the next mathematical standard or big idea. The first slide of each flipchart displayed on the interactive white board was the Common Core State Standard for Mathematics along with the learning targets. As the units developed each week, the number of slides within the flipchart increased.

At the beginning of the year, the two teachers developed procedures and administered a baseline assessment to evaluate the students' current performance levels. The assessments were part of the instruction process, not apart from it (Popham, 2011). With the data collected, the teachers shared learning targets and the criteria for success. To begin each math lesson, students sat on the floor in the front of the room with a small dry erase board and marker. The teachers used an interactive whiteboard as a means to model problems. Students took part in the instruction process by standing next to interactive whiteboard and manipulating the information to explain problems and show their work within the flipchart. By using an interactive whiteboard, the speed of questions displayed and the delivery of instruction decreases lag time within the math lesson (Zevenbergen \& Lerman, 2008).

The teachers used exit slips and posttests to evaluate the fourth-grade students on mathematical content. The teachers compiled scores onto a spreadsheet forming intervention groups. Structuring intervention groups in multiple classrooms allowed students to receive instruction that was more refined while learning concepts at their level. Through the guided instruction process, students extended their mathematical knowledge while generating ways to solve problems and testing their hypothesis to complete tasks.

\subsection{Utilizing Technology in the Classroom}

The students were motivated to do the math as well as make meaningful connections to the mathematical concepts when hands-on activities were part of the instructional lesson. Technology reinforced mathematical thinking as students developed the knowledge, skills, and disposition that engaged multiple strategies for understanding. When the teachers provided real-world applications to math, students saw a purpose for math and made connections to emerging technologies. Those technologies included classroom computers, handheld tablets to view eBooks, access to stream videos, and collaboration online. Technology engaged students and promoted active learning as a regular part of students' educational experiences (Scoter \& Boss, 2004).

The students used classroom computers and the Internet to help develop and reinforce mathematical concepts. A frequently used Internet site was IXL.com. The IXL Learning site made learning fun for students through open-ended standard aligned questions and exercises (IXL Learning, 2016). The Internet program adjusted the types of questions to the level of success of each student while at the same time provided immediate feedback guiding students through problem-solving activities (Scoter \& Boss, 2004). The IXL program provided teachers data tracking reports with content specific information. The tracking reports displayed the actual problem students missed and their incorrect response (IXL Learning, 2016). The data from the performance tracking was useful information when delivering instruction in the intervention groups.

Professionally produced math videos offered additional resources in the classroom. Videos outlined strategies to enhance and support concepts. Using visually appealing videos to introduce or reinforce a specific skill was one more way students connected with math. To provide students more time to absorb and clarify information it was helpful to pause, review, or watch the video multiple times.

\subsection{Other Variables in Math}

The teachers implemented other activities into the classroom to promote student learning and support the Common Core State Standards for Mathematics. The teachers presented multiple contexts for students to acquire information and demonstrate understanding through the key shifts in mathematics. By teaching fewer topics with greater focus, students strengthened their foundation and enhanced their ability to solve problems. Linking topics from grade to grade increased coherence so students built new understanding onto foundations from previous years. The Common 
Core Key Shifts ensured the math rigor provided authentic learning letting students apply knowledge to real-world situations (Common Core State Standards Initiative, 2016).

The mathematical discourse in the classrooms helped students talk, write, participate, and share information. Even though the teachers provided a positive climate where students collaborated and explained how they arrived at their answers, for students to be successful, there were other areas to address. Through this style of instruction, the teachers were explicit in identifying each math standard that aligned the task and assessment meeting the students' individual learning targets. When students understood the learning target and the assessment criteria, they improved their ability to self-regulate (Moss \& Brookhart, 2012).

Using assessments designed with a purpose in mind promoted learning significantly (Wiske, 2005). Teachers made instruction meaningful and used assessment to drive instruction in the classroom. To monitor student progress, the teachers used results of classroom assessments as evidence to improve and modify instruction (Popham, 2011). The teachers tracked student successes as well as content areas that needed improvement. Throughout the day, students solved mental math problems linked to their learning targets. At the end of each day, students received homework related to the learning target. Homework had a well-articulated purpose and structure to ensure high completion rates (Marzano, 2007).

Students played a more active role and took ownership of their learning when they recorded their learning targets, identified their success criteria, and charted their growth on a spreadsheet. They decided what was important and had a deeper understanding of themselves as learners. Students can be successful when they control their learning environment by monitoring their progress to meet their math goals. The best way to share their success criteria and provide evidence of learning was through their experiences and performances that represent the learning target (Moss \& Brookhart, 2012).

\section{Findings}

The findings from this two-year study revealed notable results existed among the students in the study group who received additional support in math with a combination of technology and intervention groups. It was apparent providing multiple contexts for learning presented new opportunities for students to develop their mathematical skills. Students used their prior knowledge to make sense of a mathematical problem and then extended their learning through conceptual understanding.

In the first year of this two-year study, there were 19 girls and 27 boys in the study group. Based on the results of the Washington State standardized math test, $74 \%$ of these fourth-grade students met grade-level standards. From the $74 \%$ of the students who met grade-level standards, $71 \%$ of those students scored at an advanced Level 4 exceeding state standards.

In comparison to the study group, there were 246 fourth-grade girls and 256 boys in the other Title I elementary schools in the district. From this group, $49 \%$ of fourth-grade students met grade-level standards with $19 \%$ of those students scoring at an advanced Level 4 . In the school district, there were 474 fourth-grade girls and 511 boys with $62 \%$ of the students meeting grade-level standards and $34 \%$ of those students scoring at an advanced Level 4 . In all the Washington State elementary schools, there were 37,163 fourth-grade girls and 39,605 boys. Within the state, the percentage of all fourth-grade students meeting standards was $60 \%$ with $29 \%$ of those students scoring at an advanced Level 4.

Figure 1 shows a comparison of four areas in the first year of the study. Based on the results of the fourth-grade Washington State standardized test, a notable percentage of students in the study group were more successful in meeting grade-level standards with a vast number of those students exceeding grade level standard. Therefore, the $74 \%$ of students in this study group who met or exceeded grade-level standards in math was more than the percentage of students at Title I schools in the same district, all the district elementary schools, and all the Washington State elementary schools. 


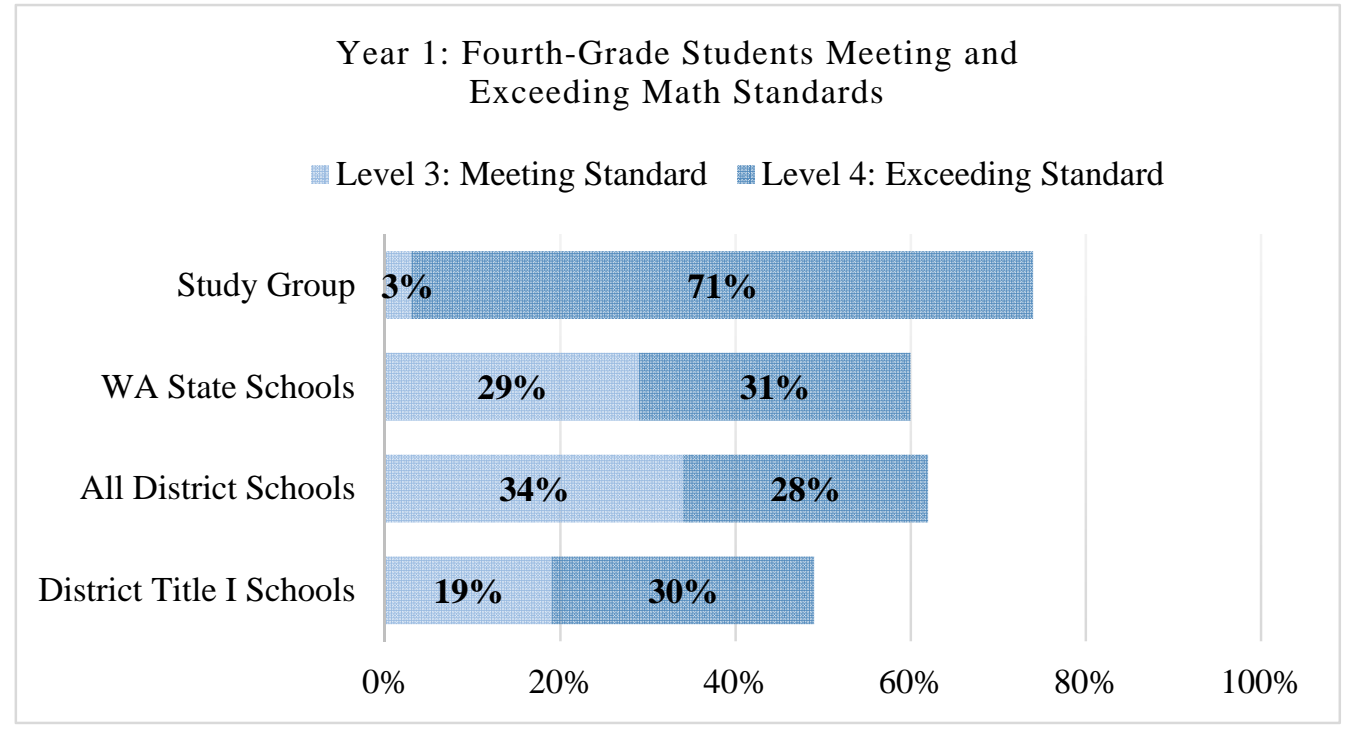

Figure 1. Comparison of the Fourth-Grade Students Meeting and Exceeding the Grade-Level Standards in Math

The second-year of this study consisted of a different group of 27 girls and 23 boys. Based on the results, $88 \%$ of these fourth-grade students met grade-level standards on the state standardized math test. From the $88 \%$ who met grade-level standards, $66 \%$ of those students scored at an advanced Level 4 exceeding state standards.

In comparison to the study group, there were 266 fourth-grade girls and 246 boys in the other Title I elementary schools in the district. From this group, $64 \%$ of fourth-grade students met grade-level standards with $30 \%$ of those students scoring at an advanced Level 4. In the school district, there were 511 fourth-grade girls and 529 boys with $70 \%$ of the students meeting grade-level standards and 39\% of those students scoring at an advanced Level 4 . In all the Washington State elementary schools, there were 37,868 fourth-grade girls and 39,295 boys. The percentage of all fourth-grade students meeting standards was $63 \%$ with $32 \%$ of those students scoring at an advanced Level 4 .

Figure 2 shows a comparison of four areas in the second year of the study. Based on the results of the fourth-grade Washington State standardized test, the study group had a higher percentage of students meeting grade-level standards. Thus within this study group, the $88 \%$ of students who met or exceeded grade-level standards in math were significantly above the percentage of students at Title I schools in the same district, all the district elementary schools, and all the Washington State elementary schools.

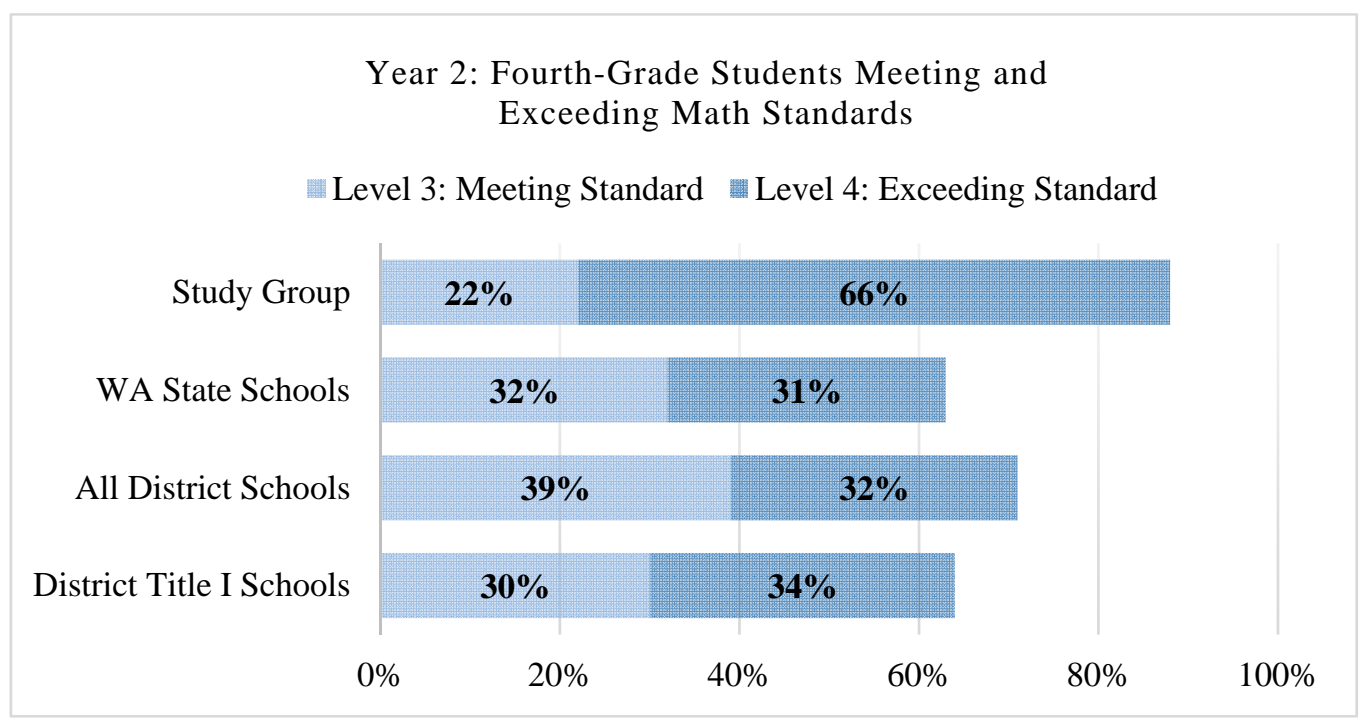

Figure 2. Comparison of the Fourth-Grade Students Meeting and Exceeding the Grade-Level Standards in Math 


\section{Discussions}

The main purpose of this study was to identify the percentage of students who would meet or exceed grade level standards if their math instruction included technology tools and intervention groups. Information collected supported the findings of this two-year study. The outcome provided insight and information on how a notable percentage of fourth-grade students at a Title I school met the Common Core State Standards for Mathematics on the Washington State standardized test.

There was a higher percentage of students in the study group meeting grade-level standards than their peers. The teachers worked as a team to support student learning while implementing multiple teaching strategies to provide opportunities for students to discover solutions that made sense to them. When students received a balanced math program, they constructed their conceptual understanding by applying new knowledge. Other key areas integrated into the math classroom included solving open-ended questions, identifying learning targets, watching videos, and using computer activities to reinforce content.

Overall, this study represented a small step in exploring the students' successes in math through integrated technology, intervention groups, and creating a positive classroom atmosphere. Therefore, the methods used in this study can help guide professional educators in their pursuit to having students meet grade-level standards in math.

\section{References}

Boaler, J. (2013). Ability and mathematics: The mindset revolution that is reshaping education. FORUM, 55(1), 143-149. http://dx.doi.org/10.2304/forum.2013.55.1.143

Common Core State Standards Initiative. (2016). Key shifts in mathematics. Retrieved from www.corestandards.org

DeVita, M., Verschaffel, L, \& Elen, J. (2014). Interactive whiteboards in mathematics teaching: A literature review. Education Research International, 2-11.

Hiebert, J., \& Wearne, D. (2003). Developing understanding through problem solving. In H. L. Schoen \& R. I. Charles (Eds.), Teaching mathematics through problem solving (pp. 3-13). Reston, VA: NCTM.

IXL Learning. (2016). IXL learning. Retrieved from www.ixl.com

Lever-Duffy, J., \& McDonald, J. (2011). Teaching and learning with technology. Upper Saddle River, NJ: Pearson.

Marzano, R. J. (2007). Art of science of teaching. Alexandria, VA: ASCD (9-32).

Mercer, N., Hennessy, S., \& Warwick, P. (2010). Using interactive whiteboards to orchestrate classroom dialogue. Technology, Pedagogy and Education online journal, 19(2), 195-209. http://dx.doi.org/10.1080/1475939x.2010.491230

Moss, C. M., \& Brookhart, S. M. (2012). Learning targets: Helping students aim for understanding in today's lesson. Alexandria, VA: ASCD.

National Council of Teachers of Mathematics (2000). Principles and standards for school mathematics. Reston, VA: NCTM.

Office of Superintendent of Public Instruction. (2016). Title I. Retrieved from www.k12.wa.us/TitleI

Popham, J. W. (2011). Classroom assessment: What teachers need to know. Boston, MA: Pearson.

Scoter, J. V., \& Boss, S. (2004). Learners, language, and technology: Making connections that support literacy. Portland, OR: Northwest Regional Educational Laboratory.

U.S. Department of Education. (2010). Elementary \& secondary education. Retrieved from www.ed.gov/policy/elsec/leg/esea02/index.html

Van de Walle, J., \& Lovin, L. (2006). Teaching student-centered mathematics: Grades 3-5. Boston, MA: Pearson.

Van de Walle, J., Karp, K., \& Bay-Williams, J. (2016). Elementary and middle school mathematics: Teaching developmentally $\left(9^{\text {th }}\right.$ ed.). Boston, MA: Pearson.

Wiske, M. S. (2005). Teaching for understanding with technology. San Francisco, CA: Jossey-Bass, (5-12).

Zevenbergen, R., \& Lerman, S. (2008). Learning environments using interactive whiteboards: New learning spaces or reproduction of old technologies. Mathematics Education Research Journal, 20, 108-111. http://dx.doi.org/10.1007/BF03217471 
Zwiers, J., \& Crawford, M. (2011). Academic conversations: Classroom talk that fosters critical thinking and content understandings. Portland, MA: Stenhouse, (7-31).

Zwiers, J. (2014). Building academic language: Meeting common core standards across disciplines. San Francisco, CA: Jossey-Bass Teacher. 